\title{
The Internet and Cosmopolitanism:
}

'[T]he use of communication media transforms the spatial and temporal organi[s]ation of social life, creating new forms of action and interaction and new modes of exercising power'

(John B. Thompson, 1995: 4)

The aim of this chapter is to present a specific case for the Internet as a communications media enabling the relational and cognitive conditions for the discursive construction of distinctive cultural and political types of critical cosmopolitanism. In contrast to an understanding of cosmopolitanism as a universal moral framework of normative principles, a 'critical cosmopolitan sociology' advanced in this chapter roots the intersections of 'self, other and world' within a relational ontology of the social, that is, in the transnational field of social relations where symbolic struggles, differences and conflicts play-out in dialogical exchanges creating distinct types of cosmopolitan relationships in moments of openness (Delanty, 2009:79; 2012b: 43; Agustín, 2017: 701; Mendieta, 2009). Indeed, as an approach, critical cosmopolitanism 'is about the [very] extension of the moral and political horizons of peoples, societies, organisations and institutions' grounded in a 'conceptualisation of the social world as an open horizon in which new cultural models take shape' in encounters between the local and the global (Delanty, 2012: 3; 2006: 27; Mignolo, 2000). However, with articulations of social mediation increasingly cutting across national borders in cultural and political flows, this chapter will argue that virtual expressions of critical cosmopolitan relations now take shape in technologically mediated networks of symbolic exchanges, communications and interactions across the Internet. With this animus, the chapter will begin by challenging the core premises of existing critical-narratives of virtual cosmopolitanism by critiquing their conceptions of the virtual and cosmopolitanism. By advancing an understanding of its status as a dominant cultural mode of sociotechnical mediation, the second section argues that (a) the Internet, as a technological expression of the virtual is embedded within the relational, cognitive and symbolic structure of the social world where (b) its transmission of cultural meanings, codes and signs across the local and the global open-up spaces for specific types of soft cultural cosmopolitan relationships found not only in expressions of curiosity and openness arising in online consumptions of other cultures, but also in a greater intersubjective reflexivness emerging out of discursive intercultural encounters. The final section connects this discursive construction of virtual spaces to harder political expressions of cosmopolitan relationships located in the affective structures of subpolitical communications where (a) networks of global justice orientated toward a shared normative culture and (b) extensions of political community shaped by an inclusive politics of recognition emerge in transnational networks of solidarity.

\section{Virtualising Social Capital: Bonding or Bridging?}

Because cosmopolitanism has its roots in the communicative structures embedded within social processes, the prospects for a virtual cosmopolitanism are contingent upon the sociotechnological capabilities of the Internet to not just mediate, but reciprocate and bridge crosscultural connections, ties and networks within and across national boundaries. For this reason, the idea of virtual cosmopolitanism as a 'cosmopolitanism...facilitated by mediated social spaces' is framed by a debate on the explicit effects of the Internet on social capital (SobreDenton, 2015: 129). By constituting 'connections among individuals - social networks and...norms of reciprocity and trustworthiness' the virtualisation of social capital has created 
a series of critical-narratives rejecting its cosmopolitan possibilities by advancing an attenuated conception of the virtual as embodying inauthentic and denigrated expressions of the social and community measured against its face-to-face counterparts (Putnam, 2000: 19). These critical-narratives can be taxonomised under the rubrics of the time-displacement thesis, the weak thesis and the homogenisation thesis. The time-displacement thesis is abstracted from a small cross-section of earlier empirical-theoretical analyses extrapolating the Internet to have corrosive effects on social capital by 'degrad[ing]' 'fragment[ing]' and 'displac[ing]' the 'real' and 'authentic' forms of face-to-face interactions (Nie and Erbring, 2000; McPherson et al, 2006; Turkle, 2011) and losing its 'affective and soul-orientated communion' (Birkerts, 1996) by creating a depthlessness of superficial, ephemeral and isolated interactions (Barber, 1998; Luke, 1998). This thesis implicates the increasing usage of the Internet in corroding collective social capital by 'individuali[s]ing' leisure time and 'disrupting opportunities for social capital formation' as it was once contextualised within the thick bonds of face-to-face social relations between friends, neighbours and relatives anchoring a sense of belonging in 'real' communities (Chen, 2013: 407; Putnam, 1995: 9; Olds and Schwartz, 2009; Hlebec et al, 2006). Along this line of reasoning, this thesis advances its critique to encompass a conceptualisation of virtual community as transmogrifying into a 'pseudocommunit[y]' parasitic on the real-life 'authentic' expressions of belongingness created in face-to-face communities, 'a progressive disavowal of the real...a culture of experiential disengagement [and] a pacification of embodied experience' (Robbins, 1999: 166), responsible for creating a sense of alienation and a loss of 'real' community (Ludlow, 1996: xv; Stoll 1995; Parsell, 2008; Dreyfus, 2001; Galston, 1999). From the logic of its premise, this thesis would not just reject the very idea of a virtual cosmopolitanism, but would also extend to its attrition of corporal cosmopolitanism situated in contiguous communities. But, this premise suffers from presupposing an erroneous dichotomy - setting the virtual in opposition to the real - which romanticises the social as an apotheosis of the latter vis-à-vis rooted in thick, contiguous, face-to-face social relations with the former collapsing into an inauthentic mimesis, simulation or hyperrealisation of the real. However, a longitudinal study by Woolgar et al (2001), coupled with drawing from our modern experiences of mediated sociality suggests the virtual to be every part of the real, not set against or replacing it, but supplementing, if not, enhancing the social (2001: 16-18).

By abstracting elements from this argument, the weak thesis challenges the possibilities of a virtual cosmopolitanism, not according to a time-displacement hypothesis, but on the grounds of its failure to replicate the strong, substantive and enduring social connections and experiences - with the cultural other - emerging out of interactions and communities of copresence. In The Experience of Virtual Communities: Cosmopolitan or Voyeur? Lee Komito (2010) argues to this effect, by asserting that most online social aggregations constitute 'normative communities' constructed, not out of strong affective ties, but from a highly instrumentalistic, egoistic individualism creating transient connections of reciprocated communications from shallow, fragile and weak cognitive ties codified around idiosyncratic engagements (2010: 146). This virtualisation of community routed across segmented, flexible and individualistic networks, according to Komito (2010), amounts to nothing more than an ephemeral coalescence of disaggregated online 'voyeurs' with a diluted sense of commitment, trust and reciprocity shaping superficial experiences of cultural diversity incapable of replicating the thick and sustained intercultural exchanges essential for cosmopolitan experiences (2010: 149). But, this thesis makes a misplaced assumption about the nature of cosmopolitanism: it is not exclusively rooted in the thick, lasting and propinquitous networks of social ties, but increasingly found in the broader, diffuse and plural networks of weak ties opening-up communicative moments, in virtual spaces, extending across not just the local, 
but also the global. As Granovetter (1973) famously argued, in his treatise on The Strength of Weak Ties, its expansive networks create wider channels, through which, more heterogeneous ideas, influences and information can disperse beyond localities broadening worldviews, exchanges, knowledge and a sense of belongingness in the world (1973: 1370-1373). Hence, it is not in the permanence of strong ties, but in the momentariness of weak ties - stretching across cultural boundaries in despatialised networks - where the greatest prospect for a virtual cosmopolitanism can be found as cosmopolitanism emerges not necessarily from longevity, but in moments of world openness. Likewise, the specific structure of these weak ties is not given its content by a narcissistic moral individualism, but by a convivial networked individualism implicit in shaping complex social configurations around multiple, diverse and diffuse networks of choice creating the intersubjective basis for the discursive and imaginative construction of community. Thus, instead of representing an imitation of a corporal community, the more abstract virtual community is a different way to imaginatively pursue a modern sense of belongingness as communities are 'distinguished, not by their falsity/genuineness, but by the style in which they are imagined' (Anderson, 1983: 6). Therefore, as an important basis for virtual cosmopolitanism, the virtual community is neither thick, concrete nor enduring, but just as legitimate as a 'mode of consciousness' shaped by 'a symbolically-constituted level of experience and meaning' with an imaginative structure 'underpinned by the search and desire to pursue a sense of belonging' (Delanty, 2010: 153).

The homogenisation thesis, on the other hand, locates its incredulities for virtual cosmopolitanism in a wider sociological tendency toward creating homophilic networks, interactions and groupings. According to Zuckerman (2014), in Digital Cosmopolitans, the electronic flows of interactions and ideas may have the theoretical capabilities to promote diverse networks across cultural borders, but, in practice, the concentration of individuals' information flows circulate within the bordered, local and homogenous networks of one's meaningful lifeworld (2014: 70). This is the unconscious effects of homophily or 'the love of the same' operating as a basic structural principle shaping levels of exposure to diversity in our lifeworlds where networks, exchanges and interactions coalesce around preferences toward commonalities of 'ethnicity, gender, age, religion, education, occupation and social class' (Zuckerman, 2014: 70). Despite its promises of greater diversity, the Internet, according to Zuckerman (2014), has only created an 'imaginary cosmopolitanism' where most interactions are among 'people with whom we have a great deal in common' (2014: 70). This too extends to the composition of virtual communities which are said to constitute 'socio-spatial enclaves' crystallising around similarities of opinion, belief, taste, interest and also prejudice shaping 'pernicious communities' of polarising thought and extremist ideology evidenced in anti-cosmopolitan movements of right-wing xenophobic-ethnic nationalisms, white supremacist groups and terrorist networks promoting intolerance, hatred and violence (Calhoun, 1998: 384; Parsell, 2008: 42). The crux of this thesis is that the Internet only strengthens the bonding of social capital vis-à-vis connections that are 'inward looking...reinforc[ing] exclusive [or] "categorical" identities' (Putnam, 2000: 22; Calhoun, 1998: 388). Despite its more extreme cases, as evidenced in pernicious communities, the homogenisation thesis exaggerates the effects of homophily: its existence does not ipso facto presuppose the affirmation of a singular, all-encompassing and homogenistic categorical identity as homophilic networks coalescing around a common-interests, beliefs or orientations can cut across a wide spectrum of cultural-historical experiences, horizons and categorical differences intersecting various markers of identity from ethnicity, age, gender to religion class and sexuality, as Calhoun (2002) admits, 'not all individual identities reflect categories of similarity' (2002: 161). Furthermore, more recent sociological empirics have shown the Internet to be conducive for 'bridging' social capital, that is, creating 'inclusive, 
outward looking networks and heterogeneous groups' 'encompassing people across diverse social cleavages' extending to appropriations of 'e-mail' (Zhao, 2006), 'blogs' (Stefanone and Jang, 2008; Qian and Scott, 2007; Herring et al, 2005) and 'social media sites' (Ellison et al, 2007; Kujath, 2011; Putnam, 2000: 22). Hence, on reflection, these critical-narratives present an unconvincing case against the notion of virtual cosmopolitanism by (a) advancing a narrow conception of the virtual as an imitation of the real and (b) presupposing cosmopolitanism as a zero-sum condition. But, the existence of virtual anti-cosmopolitan trends does not negate virtual cosmopolitan possibilities: cosmopolitanism is less zero-sum and more of an emerging condition arising, in degrees of intensity, from the discursive interactions, exchanges and nexuses of transnationally mediated social relations.

\section{The Virtualisation of Cosmopolitanism:}

This critique is not to contextualise virtual cosmopolitanism within a wider teletopia of Internet-exceptionalism or as a 'technoromanticism' (Coyne, 1999) espousing unique virtual milieux collapsing all ascriptive markers of social differentiation (Barlow, 1996; Rosseto, 1995), disembodying corporal subjectivities (Turkle, 1995; Poster, 1995) or constructing superior expressions of community (Rheingold, 1999 [1993]: 20). By these accounts, the virtual inhabits a separate realm of social existence and thus fractured from the real in a fixed virtual/real dichotomy. But, this binary is a false dichotomy: the virtual is a constitutive, inseparable and indissoluble dimension of the real mediating the cognitive, symbolic and dialogic modes of human experience, but with its increasing cultural embeddedness, the Internet - as a technological expression of the virtual - comprises a major thread in the communication fabric of the social world (Shields, 2003: 23). It is as Castells (2001) describes 'an extension of life as it is, in all its dimensions and with all its modalities' (2001: 16). As an integral component of modern culture, the virtual is entangled within the core structures of social practice mediating most expressions of everyday life - from fashioning a sense of subjectivity, organising professional life, creating personal connections, accessing information to enabling artistic expressions, religious worship and forms of political resistance (Castells, 2013: 64). Hence with its roots embedded within the symbolic and imaginative structures of social relations connecting 'neural networks' across electronic networks of communication, the Internet as a media is actively used in the construction and transmission of meaning where its relational and cognitive environments give shape to a dialectics of closure and openness, that is, between the entwined courses of both anticosmopolitan trends and cosmopolitan moments (Castells, 2012: 5; Beck, 2006). But, its capability to disperse and propagate symbolic meanings across cultural boundaries via digital communications has greatly enhanced its cosmopolitan possibilities. With the Internet positioned at the centre of a global communications environment, modern expressions of the virtual, in all its banal, routinised and habitual practices, now increasingly take the shape of hyperchaotic, instantaneous and deterritorialised digital flows 'de-stabliz[ing] old hierarchies of scale' 'compressi[ng] [space] and de-sequencing time' by stretching the contextuality of social life and its symbolic forms across national frames of reference (Sassen, 2004: 301; Castells, 2000 [1996]: 77; 2010: 21; 2001: 3). These cultural flows of information, signs, images, ideas and ideologies, circulating throughout global network scapes, attribute to shaping new imaginaries of the world by expanding the spatial horizons of our cultural experience, understandings and worldviews from outside our immediate locale (Appadurai, 1995: 35). Hence, it is in this 'global [electronic] cultural economy' where the cultural circulations of symbolic flows can open-up multiple, diverse and interactive spaces broadening cultural exchanges, consumption and contact around expressions of curiosity and commonalities of interest. (Appadurai, 1995: 32). However, these electronic flows of cultural globalisation do not constitute a cultural homogenisation or westernisation vis-à-vis the 
subsumption of diverse cultures under a single dominant western model, but, instead, as Held et al (2000) contends, creates a broadening of opportunities and spaces for cultural pluralism, creolisation and hybridisation with greater interconnectivity from transnational circulations of international cinema, foreign music, $\mathrm{TV}$, fashion, news, food, radio, languages to communications, exchanges and politics (2000: 374). As Norris and Inglehart (2009) contend, the intensification of electronic interconnectivity across the world has created a shift from national to cosmopolitan communications:

\begin{abstract}
'we follow real-time news of events in Darfur or Baghdad on our laptops and Blackberries. Headlines about Barack Obama's victory instantly surged around the globe connecting Kenyans celebrating in local villages with Americans rejoicing in Times Square. Travellers have access to Internet cafés in Bali, CNN in Doha Airport, or Die Hard movies in Beijing. Satellite TV from Al Jazeera and Al Arabia broadcasts reality television shows, music clips and images to 200 million Arab speakers from Morocco to Syria. People...in Belgium, the Netherlands, or Switzerland can receive dozens of foreign-language channels from Britain, Germany, Italy and France' (2009: 7).
\end{abstract}

Thus, the cosmopolitan potential of the Internet is situated in its cultural status as a core anchorage point for transnational mediations of social practice - contextualised within its rich, imagistic and linguistic virtual landscapes - opening new symbolic spaces of intercultural contact across the local and the global, a type of world culture, as described by Hannerz (1990), where 'increasing interconnectedness of varied local cultures [and] 'network[s] of social relationships' have created 'distributed structures of expression' and 'flow[s] of meanings' across borders (1990: 237-349). In this sense, cosmopolitanism implies a 'postwestern register of meaning...located neither on the national nor global level, but at the interface of the local and the global' (Delanty, 2012: 41). However, as cosmopolitanism implies a deeper cultural engagement with the other, these plural transnational spaces do not constitute cosmopolitanism per se, as it is more than a simple condition of plurality, but offer important preconditions for an ontological framework of specific cosmopolitan relationships: a soft cultural cosmopolitanism as a type of 'cultural omnivorousness' can be located in 'mode[s] of managing meaning... an intellectual and aesthetic stance of openness toward divergent cultural experiences' (Hannerz, 1990: 238-239), a 'curiosity about other cultural values' (Delanty, 2013: 221) and a reflexivness of one's own culture evidenced in a recognition and tolerance of cultural diversity (Urry, 1995: 167). The notion of cultural openness as 'an expression of interest, curiosity and willingness to recognise, engage and learn about the Other' has been in evidence across the Internet in broader patterns of transcultural consumption, as indicated from a quantitative analysis of Eurobarometer data, where Verboord (2017) identified 'positive associations' between cultural openness and the everyday online practices of downloading, web-searching and consuming foreign books, television, film, and music (2017: 476). In deeper, more reflexive cultural contact shaped by direct intersubjective engagements, McEwan and Sobre-Denton (2011) showed from an analysis of 'INTASU' (a Yahoo group page) that thicker interactions, exchanges and translations emerging out of intercultural communication facilitated cross-pollinations of social and cultural capital attributing to the discursive construction of a 'third-culture community' with its own normative structure of social rules, customs and codes of behaviour (2011: 256). Resonating with these findings, in a cross-cultural educational project set across the social network 'Space2cre8' Hull et al (2010) found cosmopolitan moments emerging in dialogical exchanges stimulated by 'intercultural triggers' where courses of critical selfreflection were evidenced in immediate shifts in attitudes, understandings and actions 'becoming for a time hospitable communicators able to recognise the Other in-themselves' (2010: 361). These generative processes of cultural cosmopolitanism found in 'creating new ideas, perceptions and interpretations of problems' emerging from intercultural contact typify the communicative, symbolic and imaginative structures enshrined in shaping virtual 
cosmopolitan communities. But, with the formation of these communities constituted by its imaginative possibilities, they can radicalise invoking a 'radical imaginary' abstracted from wider symbolic materials of 'social imaginary significations' creating critical, transgressive and transformative projects where the institution of society is collectively imagined anew shaping spaces of tension, conflict and sociopolitical praxis (Castoriadis, 1987: 369). Therefore, this generative-cultural imaginary assembling communities-in-themselves can radicalise and transmutate into transformative-political communities-for-themselves vis-à-vis as communities of dissent where the imaginary becomes 'the staging ground for [collective] action' orientated toward the actualisation of 'imagined worlds' (Appadurai, 1995: 3-8). This radicalisation of the imaginary informs the critical component of the cosmopolitan imagination: its orientation toward a normative critique of social reality and search for imminent possibilities of self/societal transformation emerging out of dialogical encounters with the other (Delanty, 2012: 41). Hence, the normativity of critical cosmopolitanism is bound up with 'the extension of the space[s] of the political' (Delanty, 2012: 3; Rumford, 2012: 5).

\section{A Virtual Cosmopolitics?}

The radicalisation in the content of the imaginary - as an expression of collective resistance increasingly mobilises across the geopolitical boundaries of the state challenging concentrations of global power where transnational grievances cluster around supranational institutions and its imposition of a socioeconomic model shaping the 'top-down hegemonic, neocolonial and neoliberal forces of globalisation' (Bardhan and Sobre-Denton, 2015: 136). Because this imaginary is not just embedded, but shaped, according to Appadurai (1995), in transnational forms of social practice, it not only reflects, but crystallises around a heightened global consciousness politicising the systemic ramifications of 'global risks' created by incumbent power structures throughout transnational public-spheres across civil-society (1995: 31; Beck, 1999: 39). The discourses of global risk - from war, poverty, famine to financial collapse and climate change - are framed by a notion of global justice constituting a new master-frame in which to mobilise subversions of dominant cultural codes in an extrainstitutional subpolitics evidenced in the stretching of collective action, resistance and struggles across national borders (Strydom, 1999: 69; Beck, 1999: 39). With its status as an expansive articulation of cultural openness and inclusiveness, the concept of global justice as 'a concern for matters of justice...extend[ing] beyond the borders of one's state' is a dominant political expression of critical cosmopolitanism as it can connect and unite a wide spectrum of differences in political, cultural and ethical orientations, across borders, in transnational expressions of collective actions mobilising around common grievances (Brock, 2012: 341). But, the virtual prospects for these political expressions of a critical cosmopolitanism are framed by a debate on whether political spaces, over the Internet, can be democratising or politically polarising? On one side of this debate, the Internet with its decentred, instantaneous and horizontal communications has been envisaged as conducive to democracy by creating open and inclusive transnational political spaces comparable to a 'global electronic agora' (Castells, 2001: 139), a 'global public-sphere' (Volkmer, 2003: 11) or 'a global civil-society' (Kaldor, 2003: 585) where the communication field of global politics and the structure of political communities are said to transnationally extend across social, cultural and political boundaries. On the other side of this debate, the Internet has been viewed as weakening incumbent democratic structures by creating isolated publics with homogeneous compositions demarcating political communities with reference to differences in political orientations and opinions where, according to Calhoun (1998), the 'compartmentali[s]ation of community is antithetical to the social constitution of a vital public sphere' (1998: 389). Resonating with Calhoun (1998), Habermas (2006) contends that 
this deterritorialisation of political publics has led to a denigration of politics, a rupturing and fragmentation of public-opinion and discourse:

\footnotetext{
'In the context of liberal regimes, the rise of millions of fragmented chat rooms across the world tends instead to lead to the fragmentation of large but politically focused mass audiences into a huge number of isolated publics. Within established national public spheres, the online debates of web users only promote political communication, when news groups crystallize around the focal points of the quality press, for example newspapers and political magazines' (2006: 423).
}

Along similar lines, Sunstein (2001) asserts that with its increasing customisation, the Internet caters political information around personal preferences shaping a 'daily me' intensifying a personalisation of politics subjectively filtered with 'preferred points of view [structured] along divisions of race, religion, ethnicity, nationality, wealth, age [and] political conviction' necessitating the formation of 'deliberative enclaves' and polarisations of political publics (2001: 4). This cyber-balkanisation is given a degree of credence with increasing corporate-state expropriations of metadata and complex algorithms to construct user profiles, as Bassetta et al (2017) notes, the algorithmic architecture used by Facebook filters selections and sequences of information based on a system of probabilistic relevance abstracted from users' personal metadata (2017: 63-64). But, as with the homogenisation thesis, the premise of cyber-balkanisation exaggerates the marginal/peripheral existence of extreme forms of fragmentation as characteristic, if not totalising of all online political spaces. However, these technological advances relate to another objection to its democratic potential by colonising its networks with new expressions of politico-economic power with cultural communications subject to a post-panoptic state-corporate surveillance apparatus extracting, categorising, retaining and commodifying almost all transactional metadata and content data (IP addresses, phone numbers, e-mail addresses to the verbatim content of transmissions) (Bauman, 2013: 65; Lyon, 2010: 325-326). This datafication of users' communications, thoughts and personal activities constitutes, according to Ceyhan (2012), a new power dynamic with velocity and scope - a 'new modality of [bio]power' influencing, shaping and controlling most biosociological dimensions of individuals' lives (2012: 39). But, this technique of power is more embedded, hidden and silent operating on the level of cultural practice, as Beer (2015) and Lash (2010) suggest, it is algorithmic, protocological and posthegemonic manifesting in 'systems of management' as an 'everyday neoliberalism' where metrics, data and analytics increasingly shape performances of the social world (2009: 987; 2007: 67). Despite its modern relevance, these datafication arguments fail to frame new technological assemblages of domination within a wider dialectics of power and resistance by placing too much analytic focus on power without acknowledging its shaping of new virtual techniques, repertoires and spaces for resistance.

In contrast to conceptualising it as a system of networks with isolated publics, the Internet is more a 'bow-tie structure' where common interests cluster around topical categories intermeshed by networks of hyperlinks structured by peer-recommendations, editing and filtering mechanisms (Benkler, 2006: 27). This intertwined structure does not preclude expressions of a daily me, which do exist, but is more representative of a 'see-for-yourself' culture embodied in practices of sharing, tagging and linking references to political arguments in webs of hyperlinks acting to connect disparate topics, perspectives and orientations across a wide spectrum of critical publics (Balkin, 2006; Benkler, 2006). By situating the Internet in-between the polarities of extreme inclusiveness/openness as a 'global electronic agora' (Castells, 2001) or extreme exclusiveness/closure as networks of isolated publics (Habermas, 2006; Sunstein, 2000), it can be seen more as a constellation of networked publics where communication spaces form discursive enclaves that can (a) remain isolated/disconnected or (b) can be potentially democratising by connecting to wider public- 
spheres both vertically (stretching across time/space in other avenues of the mass-media) and/or horizontally (by overlapping with different publics (Marireder and Schlögl, 2014: 690; Benkler, 2006).

In this sense, the conceptualisation of networked publics can give a greater account of its democratising potential in expressions of a transnational subpolitics where multiple, diffuse and plural compositions of critical publics and counterpublics can vertically/horizontally connect across borders in articulations of a post-foundational politics giving rise to a cosmopolitics characterised by a communicative diversity with an inclusiveness of voice cutting across cultures, languages, religions and political and moral orientations (Marchart, 2007: 176; Johnson et al, 1994: 6-7). As a discursive expression of a subpolitics, these networked publics foster articulations of transnational solidarities and form 'postnational communities of risk' codifying around common elements in value-systems, a shared ethics, commitment and dedication to issues of global risk centring on 'the universali[s]ed demand of humanity, ecology and sustainability' (Rai and Cohen, 2012: 152; Beck, 1999: 16). Its networks consist of a wide spectrum of distanciated identities, solidarities and collectiveidentities stretching across geographical borders in mobilisations of political resistance evidenced, according to Kurasawa (2004), in the alternative globalisation or global justice movements (2004: 235; Staggenborg, 2012: 163). These movements have a diverse social base cutting across different ideological networks - from socialists, feminists, to environmentalists and anarchists - composing various cultural backgrounds, but with multiple belongings and flexible identities, they can converge, connect and unite around shared moral and ethical commitments (Edwards, 2014: 161; Della Porta and Tarrow, 2005: 239-240). The moral content of these political movements reflects a specific type of cosmopolitan relationship: the search, desire and discursive construction of a shared normative culture shaped by 'the formation of a moral consciousness rooted in emotional responses to global issues, [a] concern with global ethics based on shared values, putting the non-national interest before the national interest' (Delanty, 2012: 44). In this sense, cosmopolitanism is 'constitutive of a new politics' with a strong ethical-moral content typified by mobilisations for global justice as it organises movements, in communicative engagements, across virtual networked publics and converges throughout urban spaces in collective political action (Delanty, 2012: 44; Castells, 2012: 11). These waves of demonstrations, rallies and marches against incumbent power structures utilise electronic communications to internetwork across virtual spaces, media platforms and transnational activist networks (ATTAC, PGA, WSF) to mobilise resistance across the globe evidenced in the G8 summit in Genoa in (2001); the European summits in Barcelona and Florence in (2002); the G20 in London (2009); Occupy Wall Street movement in New York (2011); the G20 in Brisbane and, most recently, in Germany where over 50,000 protestors, demonstrated, marched and protested against the G20 summit in Hamburg (2017).

This transnational subpolitics can also exhibit a weaker form of cosmopolitan relationship where, instead of its stronger sense, as a shared normative culture, it can be encapsulated in virtual extensions of political community organised around an inclusive politics of recognition. The specificities of this relationship, according to Delanty (2014), can be characterised by "the cosmopolitan ethic of a "solidarity among strangers" [where] [e]xpressions of solidarity...illustrate a...level of engagement with the other' (2014: 221). This political type of virtual cosmopolitanism can be evidenced in recent mobilisations of a global solidarity march coordinated across social media and mobilising in urban spaces, throughout the globe, in response to the derogatory-sexist, xenophobic and hateful rhetoric espoused by the Trump administration which encompassed over two million people and spread to 161 countries, across all 7 continents (Khomami, 2017; Fishwick et al, 2017). This 
specific demonstration of virtual cosmopolitanism (as existing in online communications) typifies what Fenton (2012) describes as 'a politics that makes a virtue out of a solidarity built on the value of difference...go[ing] beyond a simple respect for otherness and involv[ing] an inclusive politics of voice' (2012: 152). Because these electronic networks of solidarity exhibit a strong ethical component, the content of its communicative structures go beyond an overly procedural Habermasian (1989) notion of rational discourse as redeemed by validity-claims toward more affective-emotional structures of communication, as Wetherell (2012) contends, the currents of affect are entangled in online social practice rooted in the relational, dialogic and intersubjective flows of 'normatively organi[s]ed practices' where empathy, rapport and solidarity are discursively constructed (2012: 24-25). As theorised by Dean, (1996), Mason (2000), Bartky (2002) and Bayertz (1998), these structures of affective communication exhibited by this type of virtual cosmopolitanism embody forms of compassion, empathy, reciprocity and a notion of mutual concern which, according to Gould (2007), can shape 'transnational networked solidarities' by creating discursive nexuses between distant-strangers around a moral-disposition orientated toward mobilising cooperative projects critiquing incumbent institutional structures with a recognition of the opportunities afforded by changes in such structures for improving the lives of others (1996; 2000: 27; 2002; 1998: 17; Gould, 2007: 158; Mohanty, 2003).

These types of cosmopolitan relationships as embodied in a moral consciousness articulated in a shared normative culture and in an inclusive politics of recognition are indicative of a 'risk-cosmopolitanism' where, according to Beck (2006), an intensification of cosmopolitan interdependencies is 'bringing transnational conflicts and commonalities into everyday practices' emerging out of an increasing awareness of global risk dynamics necessitating the construction of discursive bonds, connections and ties in common commitments to global justice and politics (2006: 34). These cosmopolitan moments, as described by Beck (2006), transcend the self-absorption of cultures, languages and religions by activating, connecting and mobilising a plurality of social actors from different geographical and territorial regions in 'coalitions of action' - stimulating 'border-transcending new beginnings with new social imaginaries of political alternatives' (2006b: 34; 2006: 12-13). Likewise, for Theodossopoulos and Kirtsoglou (2013) these 'new political imaginaries' can offer a foundation for cosmopolitan communities of discontent to emerge "with [a] worldwide consciousness' engaging in cross-cultural and postcolonial critiques of a top-down neoliberal globalisation (2013: 4; Mignolo, 2000: 174; Pieterse, 2006). Importantly, as Kurasawa (2004) describes, these 'transnational modes of practice' diverge from 'thin' top-down institutional models of cosmopolitanism (see Habermas, 1996; Held, 2000; Archibugi, 1995) by expressing a 'cosmopolitanism from below' built out of interlacing lines of affinity between civic associations dispersed throughout a 'vast web of shifting nodes of commonality, shared interests and solidarity' negotiated across discursive networks (2004: 234-239). These bottom-up networks of virtual communications, according to Kurasawa (2004), structure processes of intercultural exchange, collaboration and critique that can nurture a cosmopolitanism borne out of a 'dialogical widening of horizons' where different cultural models collide eliciting forms of cultural learning, coupled with an appreciation and tolerance toward cultural pluralism (2004: 246). It is in these bottom-up responses to the human threats posed by global risks where 'cosmopolitan project[s]' committed to egalitarian universalism and a recognition for cultural pluralism can be found in the 'thick bonds of global solidarity structure[d] around intersecting modes of thought and action [articulated] in values, beliefs, narratives and symbols' (Kurasawa, 2004: 247). In closing, this affective-emotional content shaping cosmopolitan political communities exhibits an insight into a global moral consciousness where the discursive construction of alternative ethical and political models is 
mediated by structures of critical communication creating the basis, upon which, a nonfoundational, post-universalistic conception of a global ethics can be found, that is, as a sociocognitive construct 'resid[ing] more in the domain of affect...evident in ways of thinking, feelings, social movements and struggles' and as a significant dimension of online social practice constitutes, I endeavour to argue, an important expression of a virtual cosmopolitanism (Delanty, 2009: 109).

\section{Conclusion:}

In this chapter, I have presented an argument for the Internet as a significant relational, cognitive and symbolic environment for the discursive construction of distinct types of cultural and political expressions of cosmopolitan relationships. For the basis of this argument, I have challenged common presuppositions shaping understandings of both the virtual and cosmopolitanism within arguments against the notion of a virtual cosmopolitanism by asserting that (a) the virtual is not set in opposition to the real nor does it corrode it; (b) the Internet as a technological expression of the virtual does not exclusively reproduce homophilic networks nor does it create a system of isolated political publics and (c) cosmopolitanism is not a zero-sum condition nor does it presuppose strong ties for its existence. From these arguments, an understanding of the Internet is advanced in its most abstract terms as a communications media transmitting meaningful symbolic flows, across time-space, in virtual geographies where soft cultural types of cosmopolitan relationships can emerge in expressions of curiosity and openness located in the banal practices of online consumption of different cultural forms, but also from a greater intersubjective reflexiviness arising out of discursive intercultural exchanges. I have also attempted to demonstrate that harder political articulations of cosmopolitan relationships can be found in two types of subpolitical activity: (a) in the discursive construction of transnational networks built around commitments to global justice shaping orientations toward a shared normative culture and (b) in symbolic-imaginative constructions of virtual political communities with an inclusive politics of recognition mediated by affective-emotional structures of communication. Lastly, these affective structures of communication composing subpolitical networks of solidarity can offer a fruitful reference point for the sociocognitive basis for a cosmopolitan conception of a global ethics.

\section{References:}

Agustín, Ó. G (2017) 'Dialogic Cosmopolitanism and the New Wave of Movements: From Local Rupture to Global Openness'. Globalizations 14 (5) 700-713.

Appadurai, A (1996) Modernity at Large: Cultural Dimensions of Globalization. Minneapolis: University of Minnesota Press.

Archibugi, D, Held, D and Köhler, M (1998) Re-imagining Political Community: Studies in Cosmopolitan Democracy. Cambridge: Polity Press.

Anderson, B (1983). Imagined Communities. Verso: London.

Balkin, J (2004) 'Digital Speech and Democratic Culture: A Theory of Freedom of Expression for the Information Society'. New York University Law Review 79:1.

Bardhan, N and Sobre-Denton, M (2015) 'Interculturality, Cosmopolitanism and the Role of the Imagination: A Perspective for Communicating as Global Citizens' in Rozbicki, M.J (eds) Perspectives on Interculturality. New York: Palgrave Macmillan.

Bartky, S. L (2002) Sympathy and Solidarity. Lanham: Rowman and Littlefield. 
Bauman, Z and Lyon, D (2013) Liquid Surveillance. Cambridge: Polity Press.

Bayertz, K (1999) Solidarity: Philosophical Studies in Contemporary Culture. Dordrecht: Springer.

Beer, D (2009) 'Power through the algorithm? Participatory web cultures and the technological unconscious'. New Media \& Society 2009 11:985

Beck, U (1999) World Risk Society. Cambridge: Polity Press.

Beck, U (2006b) Cosmopolitan Vision. Cambridge: Polity Press.

Benkler, Y (2006) The Wealth of Networks: How Social Production Transforms Markets and Freedom. Yale University Press.

Brock, G (2012) 'Equality, Sufficiency and Global Justice' in G Delanty (2012) Routledge Handbook of Cosmopolitanism Studies. Oxon: Routledge.

Calhoun, C (1998). 'Community Without Propinquity Revisited: Communications Technology and The Transformation of the Urban Public Sphere'. Sociological Inquiry 68 (3) 373-397

Calhoun, C (2002). 'Imagining Solidarity: Cosmopolitanism, Constitutional Patriotism and the Public sphere'. Public Culture 14(1): 147-171.

Castells, M (2000) The Rise of The Network Society. Oxford: Blackwell Publishing.

Castells, M (2001) The Internet Galaxy: Reflections on the Internet, Business and Society. Oxford: Oxford University Press.

Castells, M (2012) Networks of Outrage and Hope: Social Movements in the Internet Age. Cambridge: Polity Press.

Castells, M (2013) Communication Power. Oxford: Oxford University Press.

Ceyhan, A (2012) 'Surveillance as Biopower' in Ball, K and Haggerty, K (2012) Routledge Handbook of Surveillance Studies. Oxon: Routledge.

Cohen, R and Rai, S. M (2000) Global Social Movements. London: The Athlone Press.

Curran, J, Fenton, N and Freedman, D (2012) Misunderstanding the Internet. Oxon: Routledge.

Dean, J (1996) Solidarity of Strangers. Berkeley: University of California Press.

Delanty, G (1999) Social Theory in A Changing World: Conceptions of Modernity. Cambridge: Polity Press.

Delanty, G (2006) 'The Cosmopolitan Imagination: critical cosmopolitanism and social theory' The British Journal of Sociology 57(1) 25-47

Delanty, G (2009) The Cosmopolitan Imagination: The Renewal of Critical Social Theory. Cambridge: Cambridge University Press.

Delanty, G (2010) Community. Oxon: Routledge.

Delanty, G (2012) Routledge Handbook of Cosmopolitanism Studies. Oxon: Routledge. 
Delanty, G (2012b) 'The idea of critical cosmopolitanism' in G Delanty (2012) Routledge Handbook of Cosmopolitanism Studies. Oxon: Routledge.

Delanty, G (2014) 'The Prospects of Cosmopolitanism and the Possibility of Global Justice'. Journal of Sociology 50(2) 213-228.

Gould, C. (2007) 'Transnational Solidarities'. Journal of Social Philosophy 38: 148-164.

Granovetter, M. S (1973) 'The Strength of Weak Ties'. American Journal of Sociology 78(6) $1360-1380$

Habermas, J. (2006). 'Political Communication in Media Society: Does Democracy Still Enjoy an Epistemic Dimension?' The Impact of Normative Theory on Empirical Research. Communication Theory 16(4) 411-426.

Hannerz, U (2005) 'Two Faces of Cosmopolitanism: Culture and Politics' Statsvetenskaplig tidskrift 3.

Held, D (2010) Cosmopolitanism: Ideals and Realities. Cambridge: Polity Press.

Holton, R. J (2009) Cosmopolitanism: New Thinking and New Directions. London: Palgrave Macmillan.

Hull, G. A, Stornaiuolo, A and Sahni, U (2010) 'Cultural Citizenship and Cosmopolitan Practice: Global Youth Communicate Online’ English Education 42(4) 331-367

Johnston, H, Larana, E and Gusfield, J. R (1994) New Social Movements: From Ideology to Identity. Philadelphia: Temple University Press.

Karagiannis, N (2007) 'Multiple Solidarities: Autonomy and Resistance'. In Varieties of World Making: Beyond Globalisation edited by Karagiannis, N and Wagner, P (2007). Liverpool: Liverpool University Press.

Kögler, H-H (2005) 'Constructing a Cosmopolitan Public Sphere: Hermeneutic Capabilities and Universal Values'. European Journal of Social Theory 2005 8:297.

Köhler, M (1998) 'From the National to the Cosmopolitan Public Sphere'. In Re-imagining Political Community: Studies in Cosmopolitan Democracy edited by Archibugi, D, Held, D and Köhler, M (1998). Cambridge: Polity Press.

Komito, L (2010) 'The Experience of Virtual Communities: Cosmopolitan or Voyeur?' In The Claims of Cosmopolitanism P, O’Donovan, L, Rascaroli and P, Lang 2010 135-149

Kurasawa, F (2004) 'A Cosmopolitanism from Below: Alternative Globalization and the Creation of a Solidarity without Bounds'. Arch. Europ. Social. XLV (2): 233-55.

Lash, S (2007) 'Power After Hegemony: Cultural Studies in Mutation' Theory, Culture \& Society 24(3): $55-78$

Maireder, A and Schlögl, S (2014) '24 Hours of an Outcry: The networked publics of a sociopolitical debate'. European Journal of Communication 29(6) 687-702.

McEwan, B and Sobre-Denton, M (2011) 'Virtual Cosmopolitanism: Constructing Third Cultures and Transmitting Social and Cultural Capital Through Social Media'. Journal of International and Intercultural Communication 4(4): 252-258 
Mendieta, E. (2009). 'From imperial to dialogical cosmopolitanism'. Ethics \& Global Politics, 2 (3) 241-258

Melucci, A (1996) Challenging Codes: Collective Action in the Information Age. Cambridge: Cambridge University Press.

Mignolo, W (2000) 'The Many Faces of Cosmo-polis: Border Thinking and Critical Cosmopolitanism'. Public Culture 12 (3) 721-748.

Mohanty, C. T (2003) Feminism without Borders: Decolonizing theory, Practicing Solidarity. Durham: Duke University Press.

Norris, P and Inglehart, R (2009) Cosmopolitan Communications: Cultural Diversity in a Globalized World. Cambridge University Press: New York.

Olsen, T (2005) 'Transnational Publics: New Spaces of Social Movement Activism and The Problem of Global Long-Sightedness’. Current Sociology 53(3) 419-440.

Putnam, R.D (2000) Bowling Alone: The Collapse and Revival of American Community. Simon and Schuster: New York.

Rumford, C (2008) Cosmopolitan Spaces: Europe, Globalisation, Theory. Routledge: Oxon.

Sassen, S (2004) 'Sited Materialities With Global Span' in Howard, P. N and Jones, S (2004) Society Online: The Internet in Context. Sage Publications: London.

Sobre-Denton, M and Bardhan, N (2013) Cultivating Cosmopolitanism for Intercultural Communication: Communicating as Global Citizens. New York: Routledge.

Sobre-Denton, M (2015) 'Virtual Intercultural Bridgework: Social media, virtual cosmopolitanism and activist community-building'. New Media \& Society 1-17 (2015).

Sobre-Denton, M (2015) 'Virtual Cosmopolitanism in a Networked Society' in McEwan, B (2015) Navigating New Media Networks: Understanding and Managing Communication Challenges in a Networked Society. London: Lexington Books

Shields, R (2003). The Virtual. Routledge: London.

Staggenborg, S (2012) Social Movements. Ontario: Oxford University Press.

Strydom, P (1999) 'The Challenge of Responsibility for Sociology'. Current Sociology 47(3) $65-82$.

Theodossopoulos, D and Kirtsoglou, E (2013). United in Discontent: Local Responses to Cosmopolitanism and Globalization. New York: Berghahn Books.

Thompson, A (1995) Media and Modernity: A Social Theory of the Media. Cambridge: Polity Press.

Wetherell, M (2012) Affect and Emotion: A New Social Science Understanding. London: Sage Publications.

Woolgar, S (2002). Virtual Society? Technology, Cyberbole, Reality. Oxford University Press: Oxford.

Zuckerman, E (2013) Digital Cosmopolitans: Why We Think the Internet Connects Us, Why it Doesn't, and How to Rewire It. New York: W.W. Norton \& Company. 